\title{
Research on the Detection Technology of Defects in the Bottom Joint of the Precast Shear Wall Based on Ultrasonic Imaging Method
}

\author{
Gao Rundong ${ }^{1, a}$, Li Xiangmin ${ }^{1, b}$, Zhang Fuwen ${ }^{1, c}$, Liu Hui ${ }^{1, d}$ and Leng Yubing ${ }^{1, e}$ \\ ${ }^{1}$ Shanghai Key Laboratory of Engineering Structure Safety, Shanghai Research Institute of Building \\ Sciences, Shanghai, 200032, China \\ agrdong_1@163.com, b13601902634@163.com, '2004_zhang@tongji.edu.cn, \\ d123336023@qq.com, 'eleng_yb@163.com
}

Key words: ultrasonic imaging method, bottom joint of the precast shear wall, defect

\begin{abstract}
The ultrasonic imaging method takes advantage of the technique of multichannel pulse echo, continuous plane monitoring scanning can be achieved in a single region, and no couplant is required. The experimental investigations on using the ultrasonic imaging method to detect the defects in the bottom joint of the precast shear wall are conducted. Results indicate: this method can effectively locate the position of defects in the bottom joint; to judge the defects more accurately, the ultrasonic imaging method can be combined with the widely used ultrasonic method. In future, the research on the application of the ultrasonic imaging method in practical engineering will conducted.
\end{abstract}

\section{Introduction}

In the currently vigorously promoted monolithic precast concrete shear wall structure, the bottom joint of the precast shear wall is the critical stress region. The construction of the bottom joint have the following characteristics: (1) The length of the bottom joint is usually based on the length of a piece of precast shear wall, the width equals the thickness of the wall, and the height is usually $20 \mathrm{~mm}$. (2) Most of the precast shear walls are grouted through the connected cavity. The strength of the grouting material in the bottom joint is up to $100 \mathrm{MPa}$, which belongs to ultra high strength cement-based material with no shrinkage. (3) In the bottom joint, in addition to the steel bars, there is a certain number of blocks in the grouting material, which are used to fix the height of the bottom joint. The surrounding space is generally plugged with the high strength mortar. The above characteristics make it difficult to check the defects in the bottom joint with conventional methods. It is found that the presently innovative ultrasonic imaging method has a great advantage for detecting the defects. Our research group have conducted some experimental investigations on this method.

\section{Principle of the ultrasonic imaging method}

The ultrasonic imaging method takes advantage of the technique of multichannel pulse echo. The ultrasonic wave is sent from one channel, and the other channels receive the echo. The channels take turns to send the ultrasonic wave. A complete measurement contains $n \times(n-1)$ A-scan, which is used to calculate B-scan. Real-time display of the B-scan depends on the synthetic aperture focusing technique (SAFT) [1]. Fig. 1 shows the specific schematic diagram. 


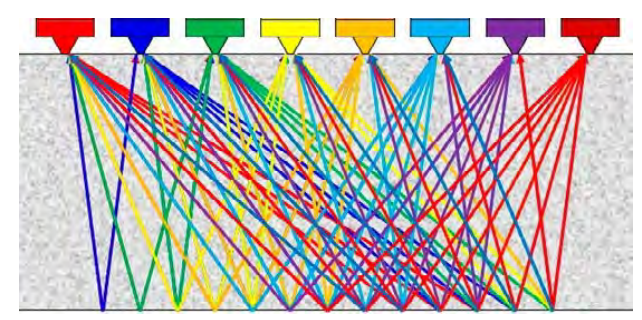

Fig. 1 Principle of the ultrasonic imaging method

The ultrasonic imaging method features the following characteristics. (1) Continuous plane monitoring scanning can be achieved in a single region. (2) No couplant is required due to the uncoupled acoustic contact technique. (3) It can overcome the influence of steel bars in concrete structures to some extent. Compare to the steel bars, it is more sensitive to defects. (4) With the data processing technique of synthetic aperture focusing imaging, the position of the defects can be determined effectively.

\section{Experimental investigations}

Setting of the defects in the bottom joint of the precast shear wall. The concrete strength grade of the precast shear wall is C40. All the vertical reinforcements have a strength grade of HRB400 and diameter of $12 \mathrm{~mm}$. All the horizontal reinforcements and tie bars have a strength grade of HPB300 and diameter of 8mm. The grouting sleeves typed GTZQ4-12 produced by Shanghai Livable Building Science and Technology Co., Ltd are used. The sleeves are casted with nodular cast iron, and the material properties meet the requirements of the standard "The grouting coupler for rebars splicing" (JG/T 398-2012)[2]. The length, external diameter and internal diameter of the GTZQ4-12 sleeve are $250 \mathrm{~mm}, 44 \mathrm{~mm}$ and $32 \mathrm{~mm}$ respectively. The grouting material with ultra high strength and no shrinkage produced by Shanghai Livable Building Science and Technology Co., Ltd is used. It has the properties of good early strength, high strength, good flowability and micro-expansion. The mass ratio of water to grouting material is 0.13 . The initial fluidity is $335 \mathrm{~mm}$, and the fluidity after 30 minutes is $290 \mathrm{~mm}$. In standard curing conditions, the compressive strength of 1 day, 3 days and 28 days are $38.5 \mathrm{MPa}, 72.0 \mathrm{MPa}$ and $123.8 \mathrm{MPa}$ respectively, which meet the requirements of the standard "Cementitious grout for coupler of rebar splicing" (JG/T 408-2013) [3].

After hoisting the precast shear walls, the height of the joint between the upper and the lower walls is $20 \mathrm{~mm}$. The joint is shaped by laying wooden blocks with normal height. The anchoring length of the reinforcements of both the upper and the lower walls in the sleeve is 8 times their diameter. The joint is sealed by the wooden formwork fixed around it to form the connected cavity, and finally the connected cavity is grouted. The design of the precast shear walls and their bottom joint refers to the standard "Technical Specification for precast concrete structures" (JGJ 1-2014)[4] and the national standard atlas "External wall panel of precast concrete shear walls" (15G365-1)[5]. Fig. 2 shows the bottom joint of the wall after grouting. 


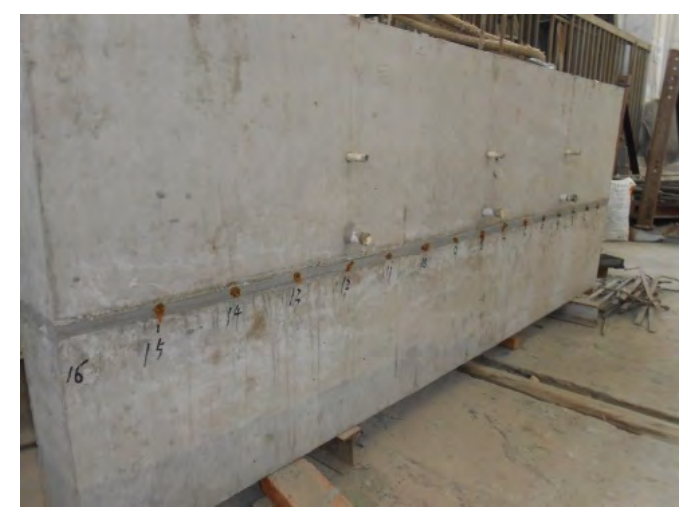

Fig. 2 The bottom joint of the precast shear wall after grouting

The defects in the bottom joint are produced by forming holes and filling with foams. The setting of the specific defects is shown in Fig. 3, the dimension unit of which is $\mathrm{mm}$. The main factors considered when setting the defects are listed in Table 1. As can be seen from Fig. 3, the length and width of the bottom joint of the precast shear wall are $2400 \mathrm{~mm}$ and $200 \mathrm{~mm}$ respectively. The circles represent the positions of the sleeves, and the black dots in the circles represent the steel bars that pass through the bottom joint. The solid squares represent the wooden blocks.

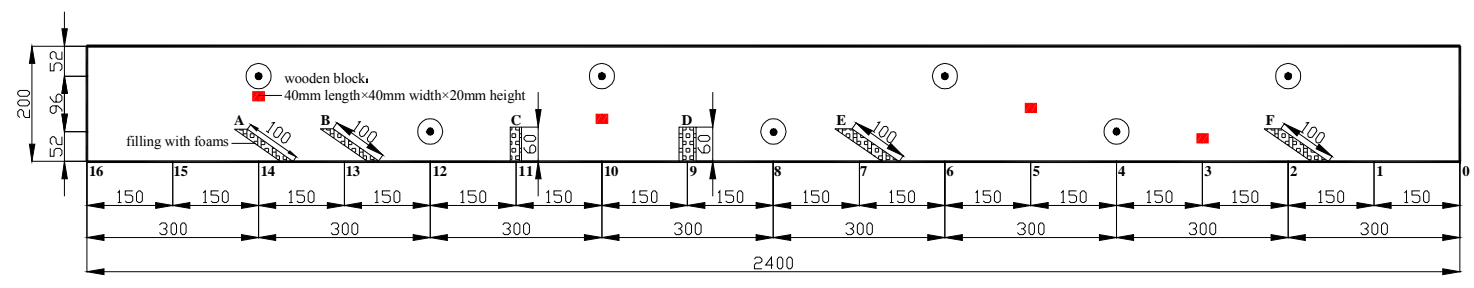

Fig. 3 Setting of the defects in the bottom joint

Table 1 The main factors considered when setting the defects

\begin{tabular}{|c|c|c|c|c|}
\hline $\begin{array}{c}\text { Defect } \\
\text { number }\end{array}$ & $\begin{array}{c}\text { Corresponding } \\
\text { ultrasonic imaging } \\
\text { testing number }\end{array}$ & Type & $\begin{array}{c}\text { Dimension of the surface } \\
\text { opening }\end{array}$ & Influencing factors \\
\hline A & 14 & $\begin{array}{c}\text { Distributed } 45^{\circ} \text { with the } \\
\text { surface }\end{array}$ & $20 \mathrm{~mm}$ length $\times 20 \mathrm{~mm}$ height & $\begin{array}{c}\text { grouting material, } \\
\text { reinforcement, wooden } \\
\text { block }\end{array}$ \\
\hline B & 13 & $\begin{array}{c}\text { Distributed } 45^{\circ} \text { with the } \\
\text { surface }\end{array}$ & $20 \mathrm{~mm}$ length $\times 20 \mathrm{~mm}$ height & grouting material \\
\hline C & 11 & $\begin{array}{c}\text { Distributed } \\
\text { perpendicular to the surface }\end{array}$ & $20 \mathrm{~mm}$ length $\times 20 \mathrm{~mm}$ height & grouting material \\
\hline D & 9 & $\begin{array}{c}\text { Distributed } \\
\text { perpendicular to the surface }\end{array}$ & $30 \mathrm{~mm}$ length $\times 20 \mathrm{~mm}$ height & grouting material \\
\hline E & 7 & $\begin{array}{c}\text { Distributed } 45^{\circ} \text { with the } \\
\text { surface }\end{array}$ & $30 \mathrm{~mm}$ length $\times 20 \mathrm{~mm}$ height & grouting material \\
\hline F & 2 & $\begin{array}{c}\text { Distributed } 45^{\circ} \text { with the } \\
\text { surface }\end{array}$ & $30 \mathrm{~mm}$ length $\times 20 \mathrm{~mm}$ height & grouting material, \\
\hline
\end{tabular}




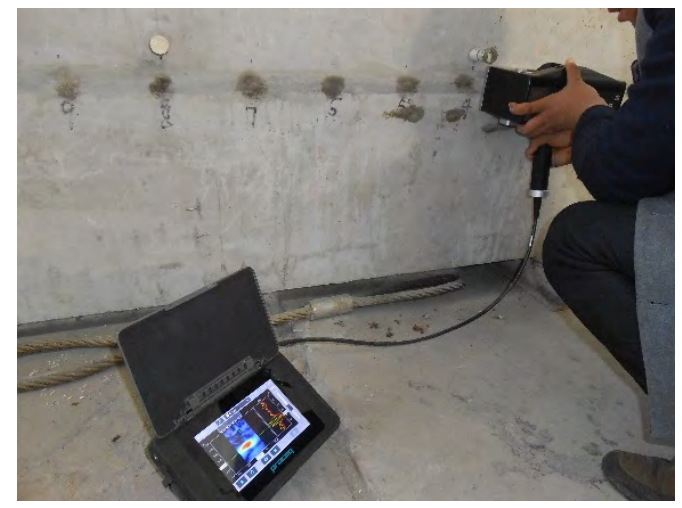

Fig. 4 Photo of detecting the defects in the bottom joint of the precast shear wall

Detecting process. Fig. 4 shows the detecting status. The detailed detecting process is as follows:

(1) Draw a line along the center of the bottom joint from one end to the other. Then mark out the points numbered $0 \sim 16$ along the line with a spacing of $150 \mathrm{~mm}$ successively.

(2) Right above the points numbered $1 \sim 15$ about $45 \mathrm{~mm}$ away from the center of the bottom joint, dot and make marks. The $45 \mathrm{~mm}$ distance is half the width of the probe surface of the ultrasonic imaging detector by Proceq.

(3) Make the midpoint of the upper edge of the probe surface of the ultrasonic imaging detector coincident with the mark right above the numbered point. Make sure that the center of the probe surface coincides with the numbered point on the center line of the bottom joint.

(4) Measure the points numbered 1 15 in turn.

Analysis of the detecting results. The detecting results of the points on the center line of the bottom joint with the ultrasonic imaging method are shown in Table 2.

Table 2 Detecting results with the ultrasonic imaging method

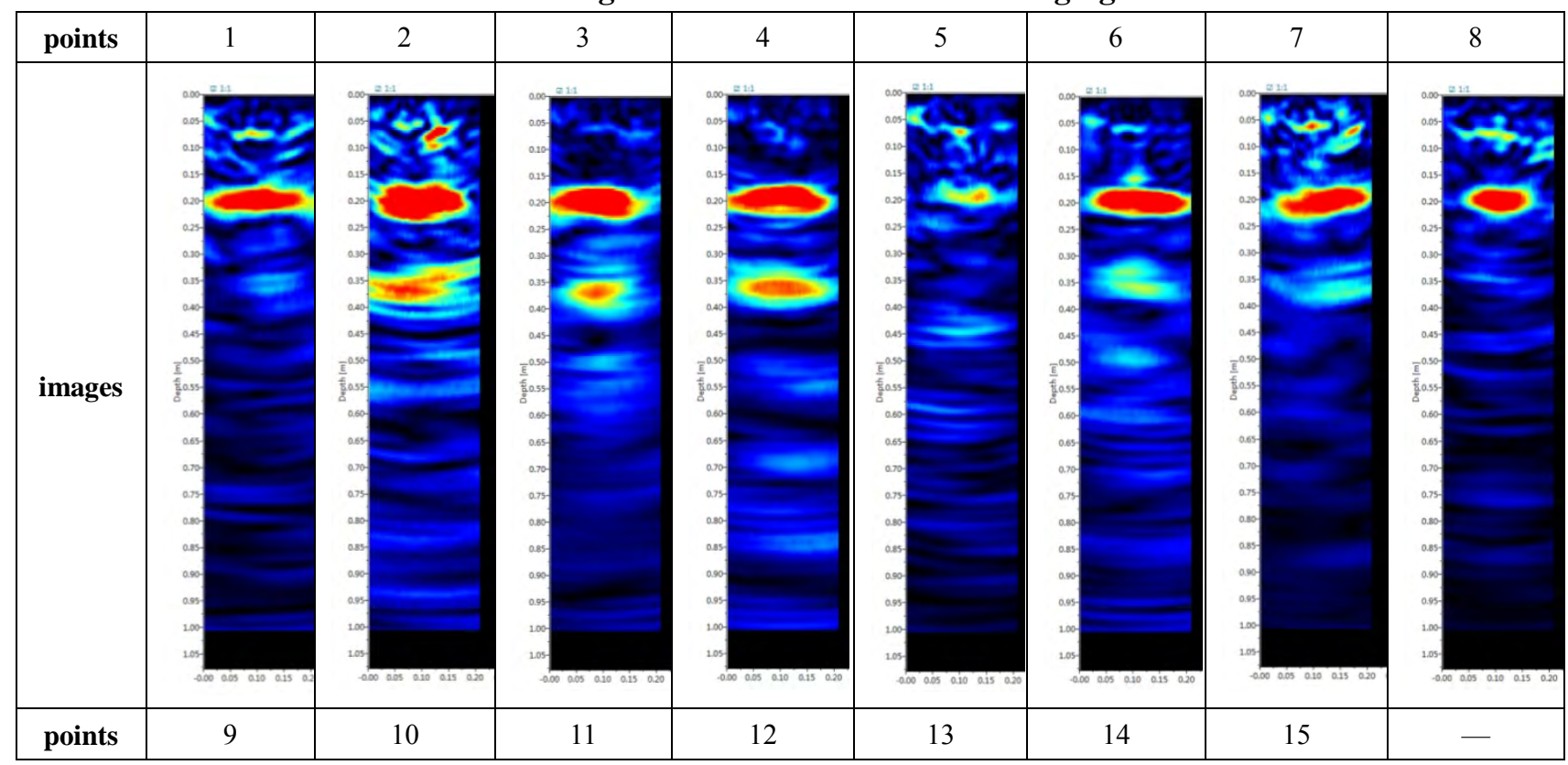




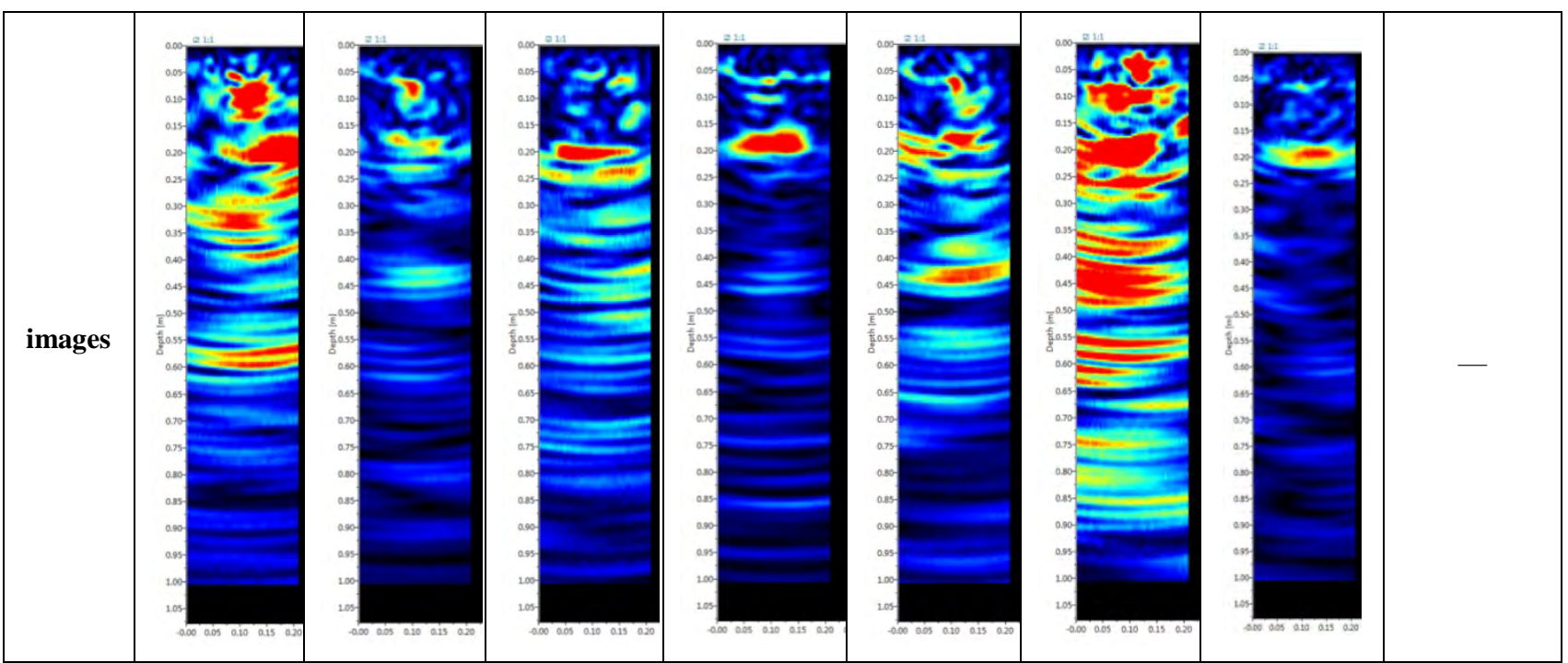

In the figures of table 2, the horizontal coordinate represents the longitudinal detecting range of the ultrasonic imaging detector, and the midpoint corresponds to the numbered point on the center line of the bottom joint. The vertical coordinate represents the distance along the width direction of the bottom joint, which is perpendicular to the probe surface of the ultrasonic imaging detector, and the origin point corresponds to the probe surface.

The defects are imaged with the synthetic aperture focusing technique. The internal defects and boundary air layer are displayed with red regions on the screen of the ultrasonic imaging detector by Proceq. The boundary air layer can be excluded according to the size of the bottom joint, then the other red regions within the boundary layer represent the defects distributed in the bottom joint. In the images corresponding to each point in table 2 , there are relatively continuous red regions at vertical coordinate of $0.2 \mathrm{~m}(200 \mathrm{~mm})$ which is consistent with the width of the bottom joint, and represents the boundary of the bottom joint. If other red regions appear within the range of $0 \sim 0.20 \mathrm{~m}$, they represent the defects. Based on this criterion, it can be judged from table 2 that there are obvious defects around the points numbered 2, 7, 9, 10,13, 14. Except for point 10, the other points are in accordance with the preset defect locations in Fig. 3. It is found with the ultrasonic method that, the sound velocity of point 10 is obviously lower than the normal points, which confirms that defect really exists around the point 10 .

\section{Conclusions}

(1) The ultrasonic imaging method takes advantage of the technique of multichannel pulse echo, continuous plane monitoring scanning can be achieved in a single region, and no couplant is required.

(2) With the data processing technique of synthetic aperture focusing imaging, the ultrasonic imaging method can effectively locate the position of defects. It is sensitive to the defects like holes with a size considerable to the height of the bottom joint. To judge the defects more accurately in the bottom joint of the precast shear wall, the ultrasonic imaging method can be combined with the widely used ultrasonic method.

(3) If used in practical engineering, due to the limitation of the operating space at the bottom of the interior walls, this method is only available for detection of the exterior walls, and the probe surface of the ultrasonic imaging detector should be arranged on the outer surface of the interior wall. In future, the research on the application of the ultrasonic imaging method in practical engineering will conducted. 


\section{Acknowledgements}

Support for this work is provided by the project from Science and Technology Commission of Shanghai Municipality (No. 15DZ1203506).

\section{References}

[1] Proceq. Pundit ${ }^{\circledR} 250$ Array Ultrasonic Imaging Scanner[R]. 2016.

[2] JG/T 398-2012. The grouting coupler for rebars splicing[S].

[3] JG/T 408-2013. Cementitious grout for coupler of rebar splicing[S].

[4] JGJ 1-2014. Technical Specification for precast concrete structures[S].

[5] 15G365-1. External wall panel of precast concrete shear walls[S]. 